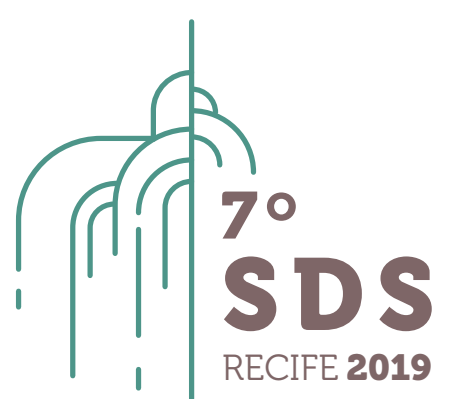

\title{
Well-being oriented Social Innovation: the use of Positive Psychology as a design framework.
}

\author{
Guilherme Toledo ${ }^{1}$, Carla Cipolla ${ }^{2}$ \\ ${ }^{1} P U C-R i o / D A D ; U F R J / C O P P E$, guilherme.toledo@puc-rio.br \\ ${ }^{2} U F R J / C O P P E$, cipolla@pep.ufri.br
}

\begin{abstract}
This paper aims at discussing the use of the Well-Being construct proposed by Martin Seligman as a theoretical framework for the design of Social Innovation. As practical and social implications of this discussion, we propose the development of alternative solutions which intentionally focus on their impact on the five dimensions which constitute well-being for the users (positive emotion, engagement, meaning, accomplishments and positive relationships), expanding the positive social impact of these solutions in direct and indirect ways, as well as a creative framework which may allow for the design of new disruptive models of consumption and value exchange between individuals and communities.
\end{abstract}

Key-words. Positive Design; Positive Psychology; Well-being; Social Innovation; Design Methods.

\section{Introduction}

At a time when economic models and work arrangements are rapidly changing, and technological developments become more and more a part of users everyday lives, design has an important role in the thinking and development of new perspectives from which to think product and service development. In this paper, we propose the use of Well-Being Theory (Seligman, 2011) as a framework for the development and re-design of Social innovation.

\section{Positive Design, Well-being Theory and Social Innovation}

\subsection{Positive Design}

Pieter Desmet and Anna E. Pohlmeyer (2013) present the notion of Positive Design as an "umbrella term for all forms of design, design research and design intention in which explicit attention is paid to the effects of design on the subjective well-being of individuals and communities." Amongst the initiatives in design research which are concerned with an intentional design contribution towards well-being, the authors mention design for experience, design for 
human capabilities, design for socially constructive behavior, design for social innovation and design for well-being.

In order to be able to compare different initiatives which are intentionally focused on subjective well-being, Desmet and Pohlmeyer propose a framework constituted of three components, which are: design for virtue (being a morally good person), design for pleasure (experiencing positive affect), and design for personal significance. The combination of all three components would result in Human Flourishing:

The idea that we advance here is that although each of the three design ingredients can serve as a guide for designing for well-being, positive design, i.e., design for flourishing, takes all three into consideration. This implies that, in our view, experience-driven design that contributes to subjective well-being by generating pleasure is positive design only if it also addresses the user's sense of virtue and personal significance. Note that positive design does not necessarily address all ingredients to the same degree; there can be an emphasis on one of them. However, in all cases, it should be ensured that the design will not impart any negative effects on the other two. For example, even though a product may not stimulate virtuous behaviour, it can still be considered to be positive design as long as it does not stimulate un-virtuous behaviour when supporting one or both of the other ingredients. (DESMET \& POHLMEYER, 2013, p. 8).

Figure 1 - Positive Design Framework

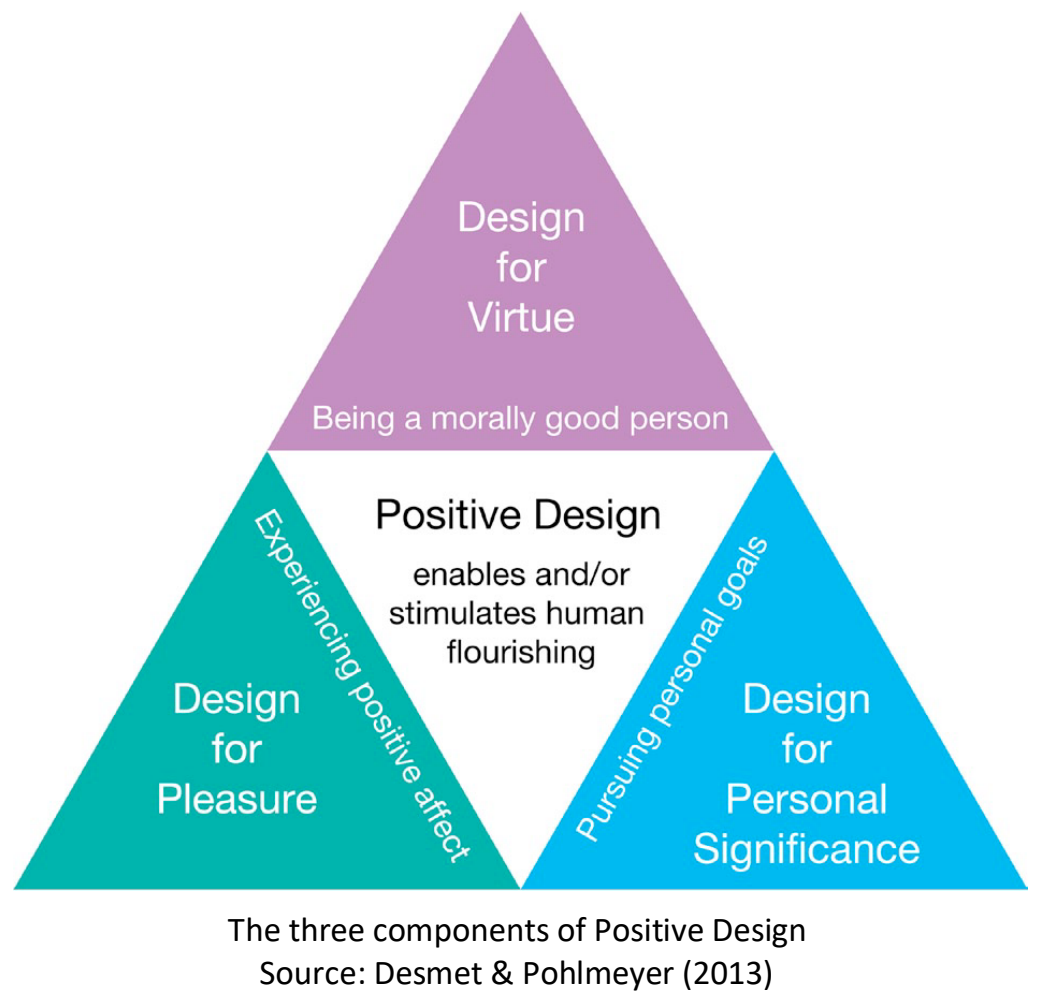

Desmet and Pohlmeyer's Model (figure 1) is strongly influenced by Seligman's Well-being Theory, but it also carries the influence of philosophical and psychological classifications from a variety of authors, which makes it a unique model for design with subjective well-being as a goal.

\subsection{Well-being Theory}

Martin Seligman's Well-being Theory (2011) is an evolution from his early theory of Authentic Happiness, from 2002; in the original theory, Seligman proposed that happiness could 
be analyzed, defined and measured by examining three components: positive emotion, engagement, and meaning. The goal of the theory was to increase life satisfaction.

\section{Components of Happiness in Authentic Happiness Theory}

i) Positive Emotion

What we feel: pleasure, rapture, ecstasy, warmth, comfort

ii) Engagement In a flow state, people describe that they think or feel nothing, merging with the object.

As Seligman identified a few inadequacies in his original theory, he pointed out the popular association of the term "happiness" with a cheerful mood, and since engagement and meaning do not refer to how people feel, they could not be truly a part of what is described as happiness. Another problem with the original theory was that it was mostly measured by self-reported life satisfaction, which is in itself a problematic measure, as research points out that "how much life satisfaction people report is itself determined by how good we feel at the very moment we are asked the question', and that would make the measurement once again too closely connected to mood. Finally, he considered the original model not to be exhaustive in its elements; the new theory was proposed in order to solve these issues.

The new theory introduces well-being as a construct constituted of five elements which can be measured independently and are pursued for their own sake, while contributing in a specific way to overall well-being. It also does not limit itself to the subjective aspects of well-being, but addresses objective components as well. The five elements are:

\section{Components of well-being in Well-Being Theory}

i) Positive Emotion The "pleasant life": a subjective aspect of happiness, including variables such as pleasure, comfort, warmth, and relating to the present.

ii) Engagement Another subjective aspect of the experience, almost opposite to positive emotion in terms of experience, encompassing notions such as the feeling of time stopping, of being completely absorbed by a task and losing self-consciousness. It can only be referred to retrospectively, not in the moment it is experienced.

iii) Meaning

Element with both subjective and objective components, referring to how meaningful an experience is to the individual; It can also be measured in an objective manner, using logic and history.

iv) Accomplishment Element which can be measured objectively, it is the pursuit of mastery and achievements for their own sake.

v) Positive

Relationships
Element with both subjective and objective components, it refers to the presence of quality relationships in someone's life. 
Source: Seligman (2011)

When the components of Positive Design are compared to the five elements of Well-Being Theory, certain differences appear:

\begin{tabular}{|c|c|c|}
\hline \multicolumn{3}{|c|}{ Components of Positive Design vs. Elements of Well-Being Theory } \\
\hline Positive Design & Well-Being Theory & \\
\hline Design for Pleasure & Positive Emotion & $\begin{array}{l}\text { Both models take this subjective } \\
\text { dimension into account. }\end{array}$ \\
\hline Design for Personal Significance & Accomplishment & $\begin{array}{l}\text { Both models contemplate } \\
\text { achievements and mastery, but } \\
\text { Positive Design approaches it from } \\
\text { the individual's subjective point of } \\
\text { view, while Well-Being Theory tries } \\
\text { to measure it objectively. }\end{array}$ \\
\hline Design for Virtue & Meaning & $\begin{array}{l}\text { There seems to be some overlapping } \\
\text { between these two categories, but } \\
\text { from different perspectives. Positive } \\
\text { Design addresses it from a moral and } \\
\text { philosophical point of view, while } \\
\text { Well-Being Theory approaches it } \\
\text { from the notion of belonging (to an } \\
\text { organisation or society). }\end{array}$ \\
\hline Design for Pleasure & Engagement & $\begin{array}{l}\text { Positive Design does not address this } \\
\text { element specifically, although it } \\
\text { could be considered part of the } \\
\text { Design for Pleasure dimension, but } \\
\text { since it competes with Positive } \\
\text { Emotion, approaching it separately } \\
\text { brings a distinctive perspective for } \\
\text { experience design. }\end{array}$ \\
\hline Design for Personal Significance & Positive Relationships & $\begin{array}{l}\text { Although, arguably, it could be } \\
\text { situated in personal significance, } \\
\text { Positive Design does not address this } \\
\text { element specifically, which also has } \\
\text { an impact on its presence. }\end{array}$ \\
\hline
\end{tabular}

Seligman argues that, since Positive Psychology is concerned with measuring and building human flourishing, it could be applied to the development of public policies, so that questions such as "How much will building this new school rather than this park increase flourishing?" could be answered in an informed way. When we extend this notion to design, we could use this framework to analyse and improve on existing solutions. Seligman continues his argument, by pointing out the risk of focusing only on subjective aspects of well-being:

Public policy aimed only at subjective well-being is vulnerable to the Brave New World caricature in which the government promotes happiness simply by drugging the population with a euphoriant called "soma." Just as we choose how to live by plural criteria, and not just to maximize happiness, truly useful measures of well-being for public policy will need to be a dashboard of both subjective and objective measurements of positive emotion engagement, meaning, good relationships, and 
For these reasons, we argue that the use of the individual elements of Well-Being Theory may offer a more complete and more objective framework for the analysis of social innovation, enabling the development of solutions which can have a deeper impact in overall quality of life.

\title{
2.3 Social Innovation
}

In "The Open Book of Social innovation", Murray, Grice and Mulgan (2010) present NESTA $^{\text {a's }}$ s definition of Social innovation:

\begin{abstract}
Innovation that is explicitly for the social and public good. It is innovation inspired by the desire to meet social needs which can be neglected by traditional forms of private market provision and which have often been poorly served or unresolved by services organised by the state. Social innovation can take place inside or outside of public services. It can be developed by the public, private or third sectors, or users and communities - but equally, some innovation developed by these sectors does not qualify as social innovation because it does not directly address major social challenges. (MURRAY, GRICE \& MULGAN, 2010, p. 10).
\end{abstract}

The authors then narrow their definition of Social Innovation in accordance to their interest in "innovations that are social both in their ends and in their means", redefining Social Innovation as "new ideas (products, services and models) that simultaneously meet social needs and create new social relationships or collaborations. In other words, they are innovations that are both good for society and enhance society's capacity to act." Commenting on this definition, Manzini (2015) mentions the increasing number of people in different contexts who need to reinvent their lives propelled by the economic crisis and the growing information and communication Technologies. According to Manzini, this is forcing many people to "radically redefine the way they live and their ideas of well-being."

Murray, Grice and Mulgan suggest that social innovation points towards a new 'social economy' with certain key features:

\section{Key features of new 'social economies'}

Intensive use of distributed networks to sustain and manage relationships

Blurred boundaries between production and consumption

Emphasis on collaboration and on repeated interactions, care and maintenance

Strong role for values and missions.

Source: Murray, Grice and Mulgan (2010)

When we examine the definition of Social Innovation, the change in people's ideas of wellbeing and the key features of emerging social economies from the perspective of Well-Being theory, it seems appropriate to use its elements as a framework to Social Innovation, not only as a way to rethink traditional experiences of products, services and models, but also as a possible

\footnotetext{
a NESTA is a United Kingdom based innovation foundation (formerly the National Endowment for Science, Technlogy and the Arts), which was established in 1998 with an endowment from the UK National Lottery, and later became an independent charity (www.nesta.org.uk).
} 
measure of their success in creating value for society.

\section{The elements of Well-Being theory in a social innovation context}

Each one of the elements in Well-Being theory can be used as way to analyze different aspects of innovations, in order to produce a greater positive impact in the community.

\subsection{Positive emotion}

Positive emotion is concerned with the immediate, present aspects of the users experience. In his analysis of emotional aspects of the user's experience, Donald Norman (2004) describes three forms of Design: Visceral Design (concerned with the way a product looks, feels and sounds to the user), Behavioral Design (concerned with the pleasure and effectiveness of use, as well as functionality, understandability and usability), and Reflective Design (concerned with subjective aspects of the experience, such as self-image, personal satisfaction, memories and meaning). These aspects of user experience are extremely important for the design of any solution, and are present in most user-centered design approaches. From a Well-being perspective, one could ask whether the solution improves the overall quality of life of the user, not just being limited to a brief pleasant experience of use, but expanding the impact of the users' experiences to their daily lives, in any kind of extended form.

\subsection{Engagement (flow)}

Csikszentmihalyi (1990) describes flow as "the state in which people are so involved in an activity that nothing else seems to matter; the experience itself is so enjoyable that people will do it even at great cost, for the sheer sake of doing it." In his research, Csikszentmihalyi observed that this 'optimal experience' was described in very similar terms by men and women of all ages and across cultures, and were consistently found in certain activities, such as sports, games, art, and hobbies. Complementary to the stimulation of pleasant emotions (which are traditionally achieved by external stimuli), good user experiences could try and create the best conditions for the user to enter a state of flow, rethinking experiences in ways which increase the users attention and their immersion in a task, as well as their sense of being in control. Games (and the gamification of experiences) are more common ways of achieving those states, but the use of physical and sensory skills, and the development of symbolic skills can also contribute to the deep engagement of the user. Flow-producing activities can also have an effect beyond the experience of use, reducing anxiety levels or helping in the creation of meaning or the establishment of purpose, which, when in a proper environment, could be further developed in positive feedback loops.

\subsection{Meaning}

Seligman (2011) defines meaning as "belonging to and serving something that you believe is bigger than the self". Social innovation can be an extremely powerful way to create this sense of belonging and to foster the creation of positive narratives with which users can identify and also build upon. When we remember that one of the key features of the new 'social economies' is a more active role by participants, experiences could be examined to understand how they can increase users participation in the creation of organizations and communities that share values and interests. Technology and digital networks have a very important role in this, as they provide inexpensive alternatives to register and exchange ideas, enabling the dynamic collective creation of virtual and physical territories where users can feel a sense of belonging.

\subsection{Accomplishment (or achievement)}

According to Self-Determination Theory (Ryan \& Deci, 2000), there are three psychological needs which are essential for an individual's growth and integration, as well as constructive social 
development and personal well-being: the needs for competence, relatedness and autonomy. The need for competence is directly related with accomplishments; similarly to what takes place in flow states, experiences can be designed in order to signal achievements and make them more evident within its own structure, but they can also be powerful motivators for the pursuit of competence in areas of the individual's own life. From a Well-being Theory perspective applied to Social Innovations, solutions could be designed in order to create conditions for the development of competences which would enable the achievement of goals, whether they are a part of the user's experience or an external goal which can be made more easily achievable by the experience provided. By developing a sense of competence, the experience has a direct impact on the individual's well-being.

\subsection{Positive relationships}

Cipolla and Manzini (2009) introduce the concept of Relational Services, which are defined as "those deeply based on interpersonal interactions, particularly favoring 'I-Thou' encounters." Based on the works of Martin Buber, the 'I-Thou' encounter involves the "ability to truly relate with the other, a mutual relationship including both dialog and encounter." When we examine the dimension of Positive Relationships which can be made possible by the experiences that take place in a service or in a system, from a perspective of relational, it opens the possibility for new models of interaction which can create relationships that extend beyond the service and enables the strengthening of communities and support networks that operate on exchanges that are not only financial, but relational. It also encourages individuals to go through the experience without the need to constrain themselves to predetermined, impersonal roles and a greater variety of benefits can be mutually produced and shared by all participants.

A very important point to the application of Well-Being Theory to the design of Social Innovation is discussed by Cipolla and Manzini, who remind us that, because of the unpredictable and uncontrollable nature of interactions involving human beings, "relational services can only be 'enabled', i.e., they need to be designed in such a way as to start up, support, and continuously sustain interpersonal encounters between the participants." That notion applies to overall application of the Well-being Theory to Social Innovation, as well-being cannot be guaranteed by the design of the user's experience, but the best conditions for its constituent elements to arise can be presented in the design of the solution, making them more likely to occur.

\section{Conclusion}

Although many product or service design solutions are able to contribute in some level to the users' well-being, it is important to consider approaches such as Positive Design, which explicitly focus on contributing to human flourishing. In this paper we suggested that the elements of Well-Being Theory could be used on their own as a framework for the re-design of social innovation which can have a direct impact on human flourishing. The argument for its use is based on the fact that i) it focuses on more than just happiness and ii) it does not limit itself to the subjective aspects of well-being, while iii) providing a framework for the identification and measurement of the presence of each independent element.

Among relevant applications of Well-being Theory as a design framework are projects which involve networks of people (physical or digital), social and relational interactions, as well as opportunities for personal development and growth. The framework can be a means to re-design existing solutions to increase their positive impact on society, as well as a creative framework which allows for the design of new disruptive models of consumption and value exchange between individuals and communities. In this way, it may help deal in better ways with the 
challenges of new economies, as well as with the creation of better conditions for well-being to be attained. Current design tools tend to address mostly the positive emotional aspects limited to the moment of the user's experience, without an intentional approach to create a positive long term impact which might outlast the experience itself. The development of a tool which takes these dimensions of well-being into account might enable designers to improve services and social innovations in ways that may contribute to the improvement of society or, at least, to minimize harmful consequences in the long term.

\section{References}

CIPOLLA, C ; MANZINI, E. Relational Services. Knowledge, Technology \& Policy (Springer), v. 22, p. 45-50, 2009.

CSIKSZENTMIHALYI, M. Flow: the Psychology of Optimal Experience. New York, NY: Harper \& Row, 1900.

DESMET, P. M. A. \& POHLMEYER, A. E. Positive Design: An Introduction to Design for Subjective Well-Being. International Journal of Design Vol. 7 No. 3: p.5-19, 2013.

MANZINI, E. Design, When Everybody Designs: an Introduction to Design for Social Innovation. Cambridge, MA: MIT Press, 2015.

MURRAY, R., GRICE, J. \& MULGAN, G. The open book of social innovation. Great Britain: NESTA, 2010.

NORMAN, D. A. Emotional design: Why we love (or hate) everyday things. New York: Basic Books, 2004.

RYAN, R. M. \& DECI, E. L. Self-Determination Theory and the Facilitation of Intrinsic Motivation, Social Development, and Well-Being. American Psychologist Vol. 55, No. 1, p. 68-78 DOI: 10.1037110003-066X.55.1.68, Jan 2000.

SELIGMAN, M. Flourish. New York, NY: Free Press, 2011. 